\title{
RNAi phenotypes are influenced by the genetic background of the injected strain
}

\author{
Peter Kitzmann, Jonas Schwirz, Christian Schmitt-Engel and Gregor Bucher ${ }^{*}$
}

\begin{abstract}
Background: RNA interference (RNAi) is a powerful tool to study gene function in organisms that are not amenable to classical forward genetics. Hence, together with the ease of comprehensively identifying genes by new generation sequencing, RNAi is expanding the scope of animal species and questions that can be addressed in terms of gene function. In the case of genetic mutants, the genetic background of the strains used is known to influence the phenotype while this has not been described for RNAi experiments.

Results: Here we show in the red flour beetle Tribolium castaneum that RNAi against Tc-importin a1 leads to different phenotypes depending on the injected strain. We rule out off target effects and show that sequence divergence does not account for this difference. By quantitatively comparing phenotypes elicited by RNAi knockdown of four different genes we show that there is no general difference in RNAi sensitivity between these strains. Finally, we show that in case of Tc-importin a 1 the difference depends on the maternal genotype.

Conclusions: These results show that in RNAi experiments strain specific differences have to be considered and that a proper documentation of the injected strain is required. This is especially important for the increasing number of emerging model organisms that are being functionally investigated using RNAi. In addition, our work shows that RNAi is suitable to systematically identify the differences in the gene regulatory networks present in populations of the same species, which will allow novel insights into the evolution of animal diversity.
\end{abstract}

Keywords: RNAi, Genetic background, Importin, Tribolium, Evolution, Emerging model organism

\section{Background}

For a long time, the identification of gene functions has been based on classical forward genetic screens where mutants are randomly generated, e.g. by chemical or transposon mediated mutagenesis. The established mutant strains are then screened for phenotypes and subsequently the disrupted gene is identified and further analyzed [1-5]. Importantly, it has been observed that the phenotypes of Drosophila and mouse mutants can depend on the genetic background of different strains, e.g. [6-13]. The same has been found for E.coli, rice and C.elegans [14-16]. In yeast, the portion of genes that are essential in only one of two closely related strains has been estimated to be about 6\% [17]. The unbiased forward genetic approach to identify gene functions has been very successful but it also limits the questions that can be

\footnotetext{
* Correspondence: gbucher1@uni-goettingen.de

Department of Developmental Biology, Blumenbach Institute of Zoology, Göttingen Center of Molecular Biology, Georg-August-University Göttingen, Göttingen, Germany
}

addressed. First, saturating screens are only feasible in a very small number of model organisms $[1-5,18,19]$. Within insects, this is true only for the fruit fly Drosophila melanogaster while a few non-saturating screens have been performed in other insects including the red flour beetle Tribolium castaneum [20-22]. The limitation to highly developed model organisms at the same time limits the scope of biological questions that can be asked. A further restriction of forward genetics is that mutant strains need to be maintained over time, which represents a significant effort feasible only with the support of large scientific communities. Moreover, the genetic tools, which facilitate stock keeping (e.g. balancer chromosomes) are not available in most organisms and are tedious to construct.

The discovery of RNA interference (RNAi) in animals [23] has opened the possibility to study gene function in many more animals and has significantly contributed to a an expansion of biological questions that are studied in terms of gene function. In RNAi, double stranded RNA (dsRNA) within cells is processed by the highly 
conserved RNAi machinery including the Dicer protein, which cuts the long dsRNA into 21mers. These are loaded into the destruction complex (RISC complex), which is guided by the single stranded small interfering RNAs (siRNAs) to mRNAs with complementary sequence. The Argonaute protein as part of the RISC complex eventually cuts the mRNAs within the region of complementary, leading to the destruction of the mRNA and consequently to a reduction of the gene product [24-26]. RNAi is an anti-viral defense system, is required for the silencing of transposons [27] and highly related processes act in post-transcriptional gene regulation, the control of chromatin and RNA polymerase II transcription elongation activity [24,28].

The RNAi response of some organisms is systemic, i.e. dsRNA delivered into the body cavity is distributed throughout the organism and enters all cells. Hence, local injection leads to systemic gene silencing [24,26,29,30]. In some organisms like C. elegans and Tribolium the RNAi effect is transmitted even from injected parents to the offspring [24,29-32].

RNAi in the red flour beetle Tribolium castaneum is robust, systemic, splice variant specific and feasible at all developmental stages [31-35]. Moreover, it is able to phenocopy genetic Null alleles at least in some instances, e.g. in the case of Tc-dfd [33], Tc-distal-less [32,36] Tc-krüppel [37] and Tc-knirps (Bucher, unpublished). The strength of the RNAi response can be experimentally modulated by varying the concentration of injected dsRNA or by varying the time between injection of the mother and collection of the phenotypic offspring [32,34,38-40].

In an ongoing genome wide RNAi screen in Tribolium (iBeetle screen, unpublished), females of the black strain [41] were injected with dsRNA of the fragment iB_00198 and were subsequently mated to pig19 males [42]. In the cuticle of offspring first instar larvae, specific labrum defects were observed with high frequency. The knockeddown gene product is an Importin $\alpha$, which belongs to the karyopherin multi-gene family of nuclear import receptors [43]. In metazoans three classes of importin $\alpha$ genes exist: importin $\alpha 1$, importin $\alpha 2$, and importin $\alpha 3$ [44]. Importin $\alpha$ proteins are nuclear import adaptors, which bind cargos containing a classical nuclear localization signal (cNLS) sequence [45]. The Importin $\alpha$-cargo heterodimer forms a trimeric complex with the actual importer Importin $\beta$, which enables the passage of the cargo through the nuclear pore complex [46]. The Importin $\alpha 1$ protein shows a tandem array of ten armadillo (ARM) repeats, where the ARM domains 1 to 4 (major site) and the domains 4 to 8 (minor site) are responsible for recognition and binding of specific cargoes $[47,48]$. All members of the importin $\alpha$ family function the same way and it has been shown that they act redundantly on many cargoes but there are also cargoes, which require a specific Importin $\alpha$ for their nuclear import $[44,45,49-54]$. In the yeast $S$. cerevisiae, estimated $57 \%$ of steady-state nuclear proteins use this import system [45]. Considering this, it was surprising that the knock-down of a gene which encodes such a widely required factor would lead to such a specific cuticle phenotype in Tribolium.

In this work, we quantitatively compare the RNAi phenotypes of Tc-importin $\alpha 1$ in two Tribolium laboratory strains, black and San Bernadino (SB). Surprisingly, we find that RNAi knock-down leads to qualitatively different phenotypes depending on the strain. Further, we show that this is neither due to a general difference in RNAi sensitivity of these strains nor to nucleotide sequence divergence between them or differential embryonic expression. Instead, we find that the genotype of the injected female determines the RNAi phenotype of the offspring. These results show that the phenotypes generated in RNAi experiments can depend on the genotype of the used strain and we suggest that a proper documentation of the strain is an essential piece of information when publishing RNAi studies in any species.

\section{Results and discussion \\ iB_00198 dsRNA targets Tc-importin a1}

The RNAi phenotype of the iB_00198 dsRNA fragment revealed by the iBeetle screen was marked by a highly penetrant and specific loss of the labrum (The iBeetle consortium, unpublished). In order to follow up this phenotype, we first analyzed the phylogenetic relationship of the targeted gene. The iB_00198 sequence is part of the coding sequence of TC000963 (Additional file $1 \mathrm{~A}$ ). Phylogenetic analysis revealed that the TC000963 gene is the single importin $\alpha 1$ ortholog of Tribolium, called Tc-importin $\alpha 1$ in the following (Figure 1, red frame; see Additional file $1 \mathrm{C}$ for aligned sequences). The Tc-Importin $\alpha 1$ protein is more similar to the mouse orthologs (Karyopherin $\alpha 1 / 6)$ than to Drosophila Importin $\alpha 1$. We checked the expression of Tc-importin $\alpha 1$ by in situ hybridization and found it to be expressed ubiquitously in both $S B$ and black embryos (0-26 h egg collection at $32^{\circ} \mathrm{C}$; not shown).

\section{Tc-importin a1 pRNAi cuticle phenotype is different in the two strains}

To test whether the labrum specific iB_00198 phenotype detected under the high throughput conditions of the iBeetle screen was reproducible and not due to off target effects, two non-overlapping dsRNA fragments of the Tc-importin $\alpha 1$ open reading frame were generated (Additional file $1 \mathrm{~A}$ and B) and injected into female pupae of the $S B$ strain with the same dsRNA concentration as in the screen $(1 \mu \mathrm{g} / \mu \mathrm{l})$. The resulting cuticles were scored for deletion or malformation of different parts of the body (Figure 2A, B, indicated in black and gray, respectively). In addition, the number of individuals falling into one of several specific phenotype classes was determined (Figure 2A, white bars). 


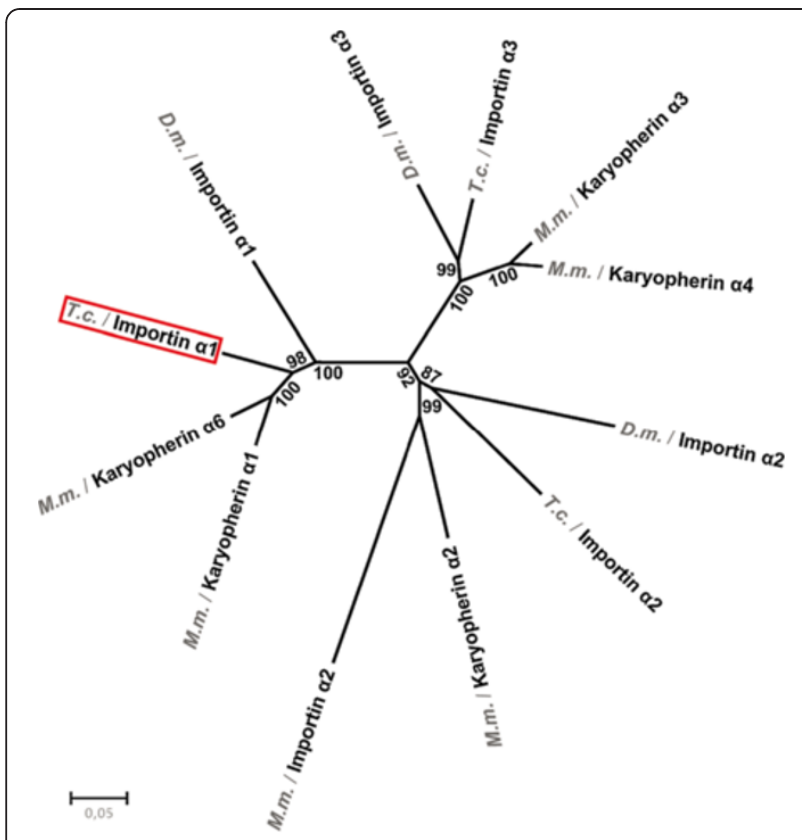

Figure 1 Phylogenetic tree of Tc-Importin a proteins. Metazoans have three conserved Importin a families (a1, a2 and a3). Tc-Importin a1 (framed) encodes a protein of the Importin a1 family. Interestingly, it is more closely related to the mouse than to the Drosophila orthologs. M. musculus has two paralogs per family while Tribolium and Drosophila have only one representative of each Importin a family. Shown is a Neighbor-joining tree with Bootstrap values for each node.

Note that the "labrum only" class represents cuticles that show defects in the labrum but not in other structures. Some phenotypes did not fit any of the classes shown and were not similar enough to group them into an own class. Knock-down using the first fragment (Tc-importin $\alpha 1 \mathrm{a}$ ) resulted in a much stronger cuticle phenotype than observed in the screen. Most frequent were abdominal malformations (93.3\%; $n=30$ cuticles), ranging from mild phenotypes in which the abdomen was constricted ("small abd", $13.3 \%$, not shown) to cuticles which showed an inversion of abdominal segments into the interior of the cuticle (abdomen inside-out: "Abd i-o", 36.6\%; Figure 2C). Defects in the thoracic segments were frequent (76.6\%) where in most cases only single thoracic segments or legs were deformed (60\%). Malformation of the head included mainly the loss $(40 \%)$ or deformation (26.6\%) of gnathal appendages ("Gnath. app."). The antennae ("At"; 40\%) and labrum ("Lr"; 46.6\%) were also often affected after Tc-importin $\alpha 1$ RNAi. In some cases, the complete head and adjacent thoracic segments were absent ("Headless", 13.3\%; Figure 2D). Dorsal cuticle defects ("Dorsal cut. def."; Figure 2E) were found in $23.6 \%$ of examined larvae. Unexpectedly, the labrum-only defects observed in the iBeetle screen (i.e. cuticles showing no other defects apart from the labrum; "Only Lr") were not observed in this experiment while overall, the defects were much more extensive. Of note, in all cases where the labrum was recorded as not being present (white asterisk in Figure 2A) this was due to complete loss of the head in the respective cuticle (black asterisk in Figure 2A). The results of the non-overlapping fragment (Tc-importin $\alpha 1 b, n=13$ ) displayed quantitatively and qualitatively similar defects with somewhat reduced strength of labral and gnathal defects and the headless phenotype (Figure 2B). This made off target effects unlikely. In order to independently check the different quality of the phenotypes, we conducted a correspondence analysis of the data and visualized the results in a xy-plot. The phenotypes in the different strains form distinct clusters confirming the different quality of the phenotypes (Figure 3).

In order to test whether this unexpected phenotypic difference was due to the selection of dsRNA fragments different from the one used in the screen (Additional file $1 \mathrm{~A}$ and $\mathrm{B})$, or alternatively, from the use of a different strain, Tc-importin $\alpha 1$ RNAi was repeated in the black strain. Both non-overlapping dsRNA fragments $(1 \mu \mathrm{g} / \mu \mathrm{l})$ were injected into black female pupae, which were mated with black males (Figure 2F-J) or pig19 males (i.e. the combination used in the screen; Additional file $1 \mathrm{D})$. The knock-down using the Tc-importin $\alpha 1$ a dsRNA (Figure $2 \mathrm{~F}$, $\mathrm{n}=22$ ) frequently resulted in cuticles with an affected labrum (86.4\%) which was either deformed (36.4\%; Figure $2 \mathrm{H}$ ) or completely absent (50\%; Figure $2 \mathrm{I}, \mathrm{J})$. In a portion of the cuticles, other head defects (antennal and gnathal: $22.7 \%$ ) or abdominal defects were found (4.5\%). Notably, the "labrum only" phenotype was frequent $(>60 \%)$. These observations were confirmed using the non-overlapping fragment with the only difference that additional dorsal cuticle defects were observed (28.6\%; Figure 2G). To further confirm our finding, we repeated the RNAi with the original iB_000198 dsRNA fragment $(1 \mu \mathrm{g} / \mu \mathrm{l})$ in the black and $S B$ strains, which resulted essentially in the same strain specific phenotypes (not shown; the original documentation of all Tc-importin $\alpha 1 \mathrm{RNAi}$ experiments is found in Additional file $1 \mathrm{E}$ ).

Taken together, these results showed that the knockdown of Tc-importin $\alpha 1$ led to different phenotypes depending on which strain was injected and that this difference was not due to off target effects. Because both non-overlapping dsRNA fragments resulted in similar phenotypes, the following experiments were done using the Tc-importin $\alpha 1$ a fragment. Importin $\alpha$ proteins are essential parts of the nuclear import machinery and have housekeeping functions [49]. Therefore, one would expect a dramatic and pleiotropic loss of function phenotype. The phenotype in the $S B$ strain matches this expectation pretty well. Also in the black strain, some pleiotropic defects are observed, which increase somewhat in number at higher dsRNA concentrations. This is an indication that the expected pleiotropic phenotype is present but strongly reduced in the black strain. 


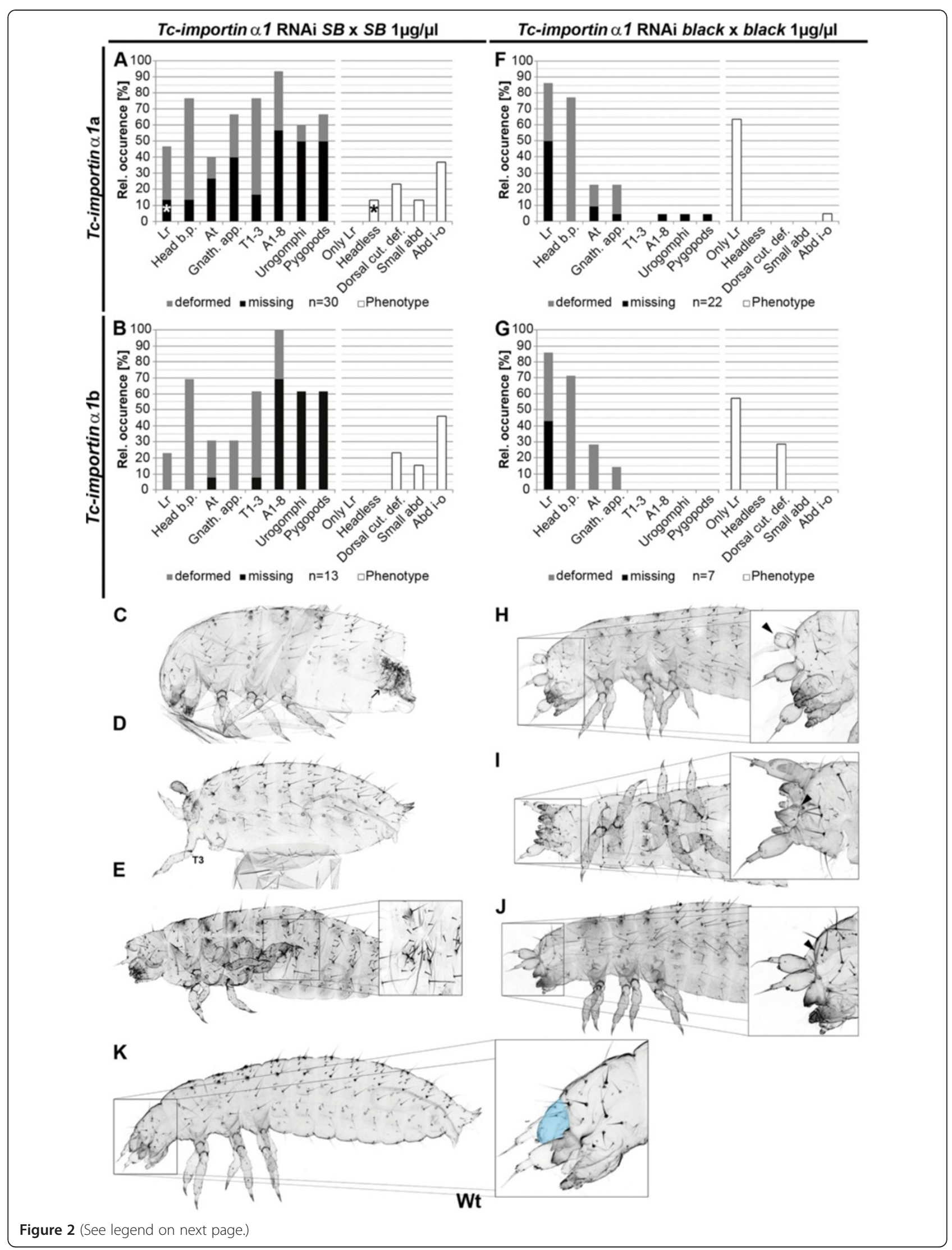


(See figure on previous page.)

Figure 2 Different Tc-importin a1 RNAi phenotypes in the SB and black strains. (A, B, F, G) Quantification of affected cuticle structures (shaded bars, left part of the panels) and frequency of phenotype classes (white bars, right part of the panels). Note that these represent two separate analyses of the same set of RNAi cuticles and that not all cuticles could be assigned to a class. (A, B) Knock-down of Tc-importin a 1 in the SB strain using two non-overlapping fragments (Tc-importin ala (A) or Tc-importin a 1b (B)) results in a similar pleiotropic cuticle phenotype. Note that the loss of the labrum (white asterisk in A) is due to loss of the entire head (black asterisk) while a "labrum only" phenotype was not observed. (C) Lateral view of a cuticle showing the abdomen inside-out phenotype ("Abd i-o" class) where the posteriormost abdominal segments are involuted into the abdomen (black arrow). (D) Lateral view of a headless cuticle which lacks most anterior structures up to the third thoracic segment (T3). (E) Ventro-lateral view of a cuticle showing a mild dorsal cuticle defect. (F, G) The knock-down of Tc-importin a 1 in the black strain using the same non-overlapping fragments resulted in about 60\% of the examined cuticles in a specific loss (I, $\mathbf{J})$ or deformation (H) of the labrum ("Only Lr" class). (H) Lateral view of a cuticle showing a deformed labrum (black arrowhead). (I, J) Dorsal (I) and lateral (J) views of cuticles lacking the labrum (arrowhead). (K) Wild-type larval cuticle (Lr is marked in blue). Lr labrum, Head b.p. Head bristle pattern, At antennae, Gnath. app. gnathal appendages, T1-3 thoracic segment 1-3, A1-8 abdominal segments 1-8, Dorsal cut. def. dorsal cuticle defect, Abd. i-o abdomen inside-out.

\section{The phenotypes are qualitatively different}

RNAi experiments tend to produce a phenotypic series depending on the amount of injected dsRNA and due to experimental variation. Hence, despite the fact that the same concentration of dsRNA was injected in all experiments, the "labrum only" phenotype found in black could represent a weak phenotype while the more widespread defects found in $S B$ could represent the stronger part of the phenotypic series. On the one hand, the additional defects that occurred in the black strain-albeit at low frequencies-could be interpreted in this way. On the other hand, the fact that the "labrum only" phenotype occurred very frequently in the black strain

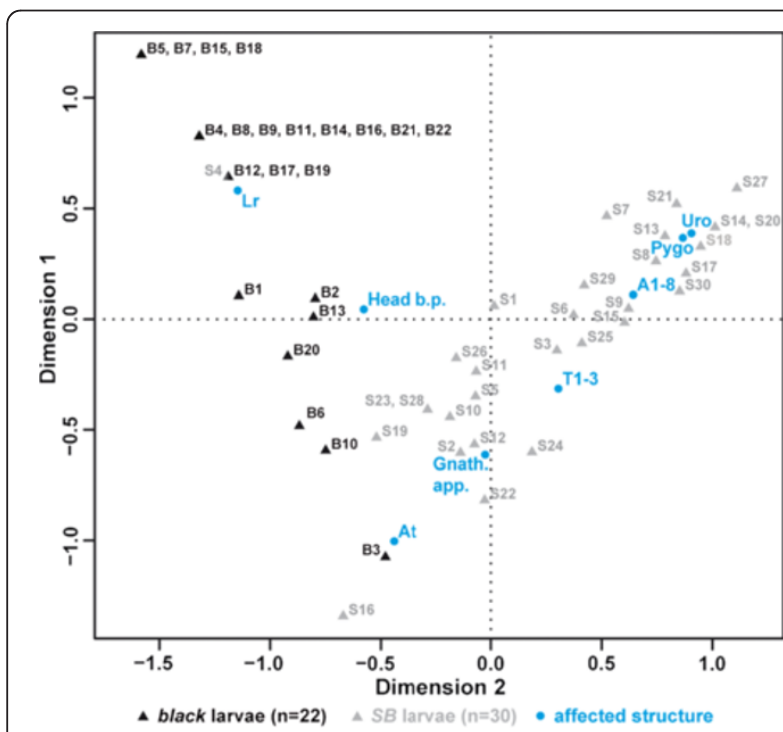

Figure 3 Correspondence analysis of Tc-importin a1a RNAi cuticle phenotypes in the black and SB background. The individual Tc-importin ala RNAi cuticles of the black genetic background (black triangles) group together at the left side of the plot (labrum, head bristles and antenna phenotypes) while the $S B$ cuticle phenotypes (gray triangles) are located more on the right side of the plot (abdominal, thoracic and gnathal phenotypes). There is not much overlap between the two clusters.
(Figure 2F,G) but never in the $S B$ strain (Figure 2A,B) indicated a qualitative difference. If these different phenotypes were part of one phenotypic series, the injection of different amounts of dsRNAs in both strains was predicted to reveal concentrations where the phenotype pattern in both strains would overlap. Therefore, we injected both lower and higher concentrations of dsRNA into both strains (Figure 4).

Injecting lower amounts of dsRNA $(0.3 \mu \mathrm{g} / \mu \mathrm{l})$ into the $S B$ strain led to a decreased frequency of cuticular defects, while their quality was similar to the $1 \mu \mathrm{g} / \mu \mathrm{l}$ experiment (compare Figure 4A with B). Specifically, the "labrum only" phenotype was not found. Using $3 \mu \mathrm{g} / \mu \mathrm{l}$ dsRNA led to an "empty egg" phenotype in all animals. Empty egg phenotypes are an indicator of very severe embryonic defects leading to the abortion of embryonic development prior to cuticle secretion resulting in empty egg shells in cuticle preparations (Figure 4C).

Knock-down of Tc-importin $\alpha 1$ in the black strain using $0.3 \mu \mathrm{g} / \mu \mathrm{l}$ dsRNA resulted in a very similar phenotypic pattern as shown for $1 \mu \mathrm{g} / \mu \mathrm{l}$ (compare Figure 4D with E). Notably, "labrum only" phenotypes were found in about $80 \%$ (Figure 4D) where the labrum was absent in $41.2 \%$. Other defects were observed with low frequency. Injection of $3 \mu \mathrm{g} / \mu \mathrm{l}$ dsRNA led to cuticles with a comparable occurrence of labrum defects but with a slightly increased portion of other cuticular defects (Figure 4E, F). As consequence, the number of "labrum only" (i.e. labrum but no other structure affected) phenotypes dropped to $30 \%$ but the labrum remained the most frequently deleted structure (40\%). Finally, we tested the effect of Tc-importin $\alpha 1$ RNAi in two other strains. We injected females of the pig19 strain (derived from the pearl genetic background) and mated them with black males. The phenotype of the offspring was intermediate between black and $S B$ injected females (Additional file 1I). In the Georgia-2 (GA-2) genetic background, the injected females became sterile not allowing judging the cuticle phenotype of the offspring (Additional file $1 \mathrm{~J}$ ). 


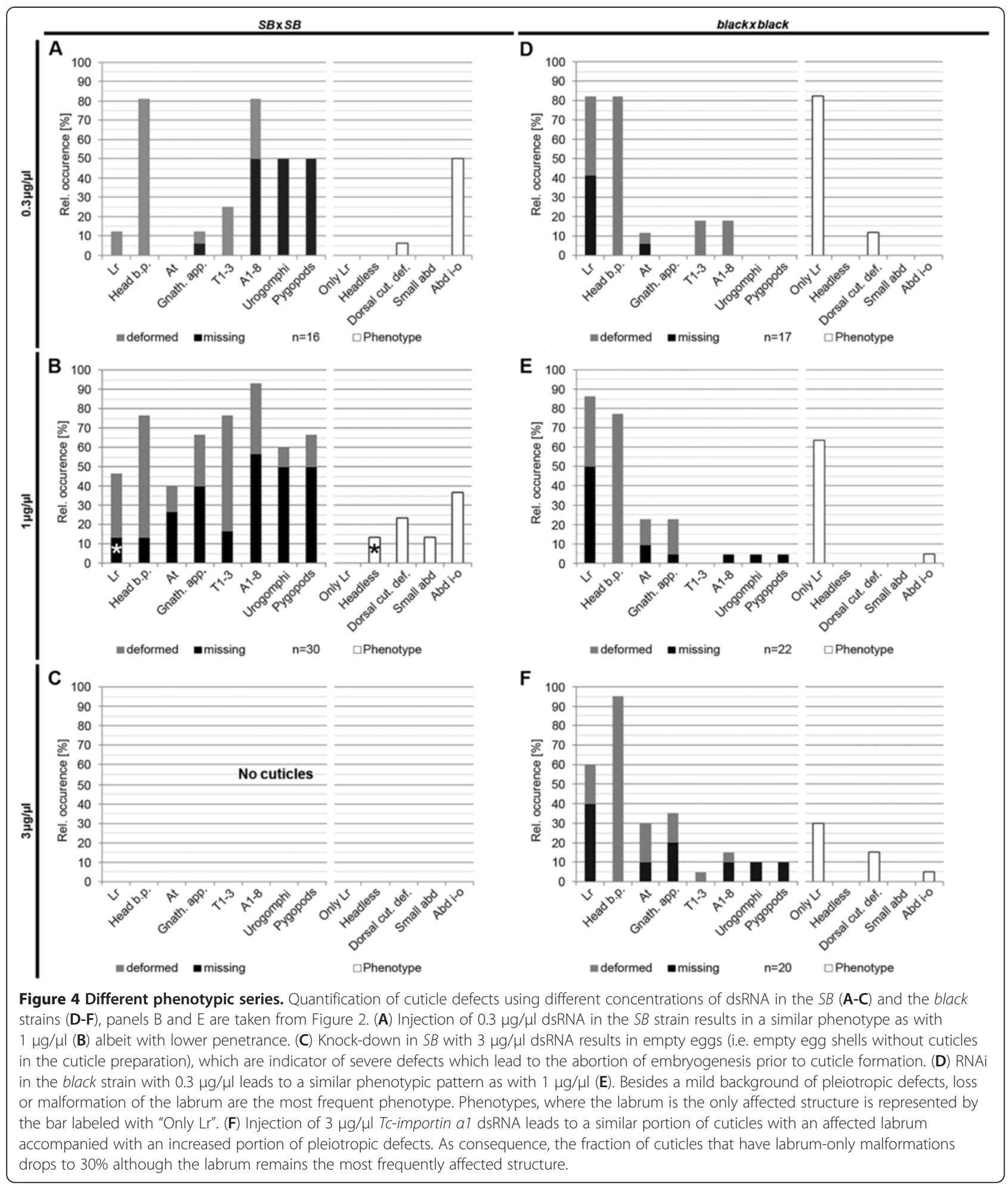

In summary, the phenotypic series generated by RNAi with the same dsRNA in different strains differed qualitatively in several respects: "Labrum only" phenotypes were found exclusively in the black strain while the abdomen inside-out phenotype always remained below
5\%. Moreover, increasing dsRNA concentrations led to a rather mild increase of phenotypic severity but even at highest concentrations the "empty egg" phenotype was not increased beyond background. In the $S B$ strain, in contrast, "labrum only" phenotypes were not found at 
all, while the abdomen inside out class was always high. Increasing amounts of dsRNA led to a significant increase of phenotypic severity leading to $100 \%$ "empty egg" phenotypes at high concentrations. At the same time, the phenotypes also show similarities: The pleiotropic defects seen in $S B$ and to a minor extent also in black represent the expected pleiotropic phenotype of a nuclear import protein.

\section{RNAi sensitivity is similar in the black and SB strains}

The different RNAi phenotypes could be due to a different strength of the RNAi response in these strains or alternatively could be due to the different genetic background, which interacted differently with Tc-importin $\alpha 1$ but not other genes. To test this, we first quantified the transcript level in the RNAi animals by qPCR. The expression was reduced by $>93 \%$ in both strains in both $0-2 \mathrm{~h}, 10-12 \mathrm{~h}$ egg collections as well as in ovaries (Additional file $1 \mathrm{~K}$ ). As a complementary means to compare RNAi efficiency in the strains, we quantitatively compared the phenotypic range induced in the $S B$ and black strains after RNAi using the same dsRNA preparations targeting four different genes.

First, we checked Tc-distal-less $(T c$-dll) and Tc-giant $(T c-g t)$, which elicit well quantifiable defects in the offspring of injected pupae [32,36]. dsRNA targeting Tc-dll was injected into both strains, 50 cuticles of the first egg collection (d 9 after injection) were analyzed regarding the number and state of the remaining leg segments. The cuticles were grouped into four different classes of phenotypic strength. In the strongest class only a coxa remained present (Level 4; Figure 5A, leftmost panel) while in the weakest class an almost complete trochanter was present (Level 1; Figure 5A, rightmost panel). The strongest phenotype was found only in black Tc-dll

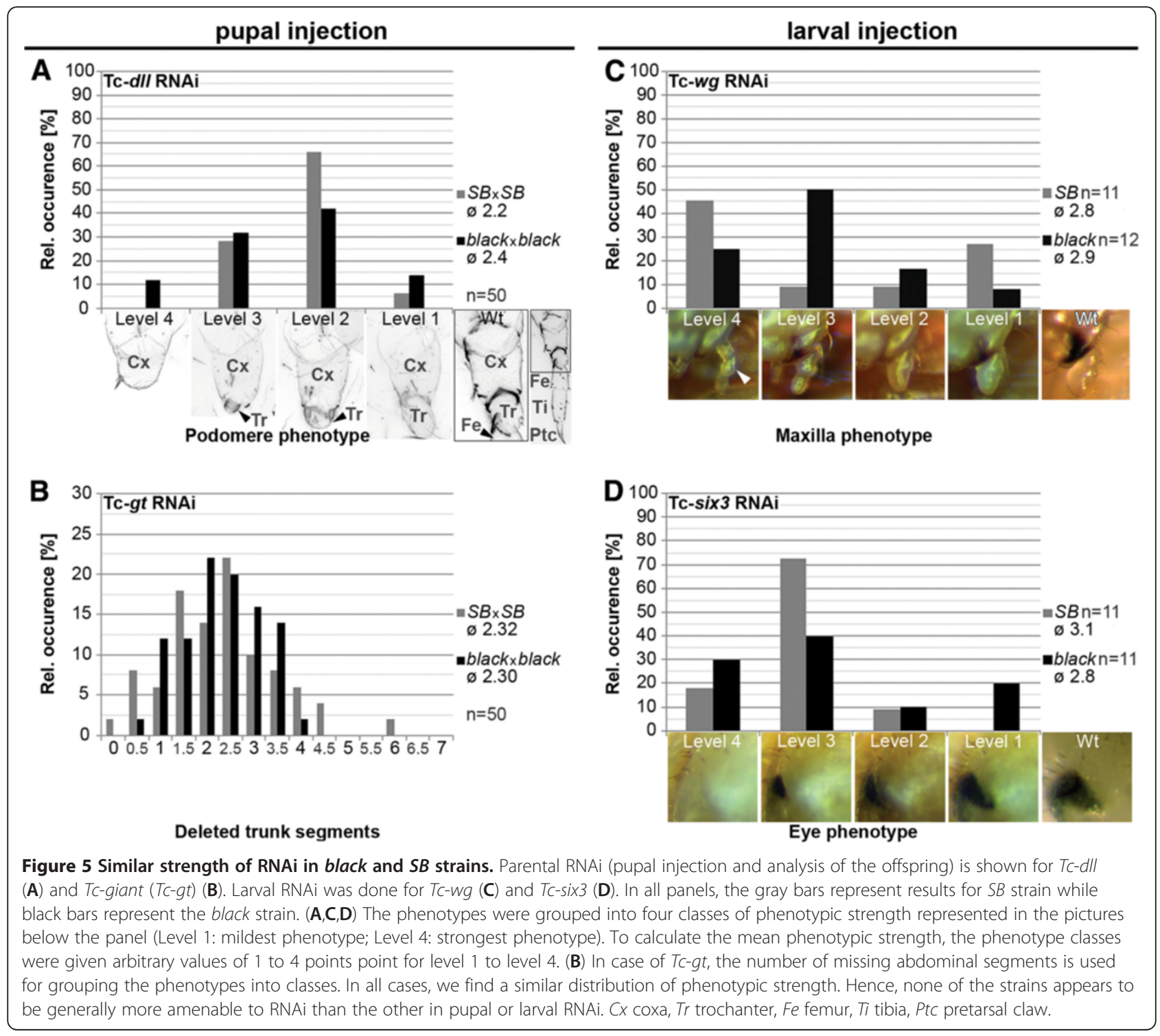


RNAi (Figure 5A, black bars), but also the mildest phenotype was observed more often in the black strain. We arbitrarily rated the four categories (one point for level 1 and four points for level 4) and calculated the average phenotype strength, which turned out to be similar (ø black: 2.4, ø SB: 2.2).

The analogous experiment was performed with $T c-g t$ dsRNA $(1 \mu \mathrm{g} / \mu \mathrm{l}, \mathrm{n}=50)$. The number of deleted trunk segments was used as measure for the phenotypic strength. This number varied from zero to six deleted trunk segments (Figure 5B). Overall, the distribution in both strains was similar, while both the strongest and the mildest phenotypes were only observed in $S B$ cuticles (Figure 5B, gray bars). Also the average of the number of deleted segments was very similar (ø black: 2.30, ø $S$ : 2.32).

Further, we performed larval RNAi for Tc-wingless $(T c-w g)$ and $T c$-six3 in order to compare the RNAi response after larval RNAi (IRNAi). Knock-down of $T c$-wg via injection of dsRNA $(1 \mu \mathrm{g} / \mu \mathrm{l})$ into late larval stages (L6) of $S B$ and black lead to pupae with reduced genital lobes, an increased distance between the pupal wings and a reduced maxillary diameter (Figure 5C). The latter was the best quantifiable indicator because the diameter is very constant in wt pupae (Additional file $1 \mathrm{G}$ ). The phenotypic series was divided into four categories (Figure 5C, panel 1-4), was rated and the average was calculated. Both strains show a comparable mean value (ø black: 2.9, ø SB: 2.8).

Tc-six3 dsRNAi injection $(0.5 \mu \mathrm{g} / \mu \mathrm{l})$ in L6 larvae led to pupae with reduced eye size (Figure 5D), which was quantified (see experimental procedures). Again, the phenotypes were grouped into four categories and the mean values were calculated (Figure 5D). Tc-six3 IRNAi resulted in slightly stronger pupal phenotypes in the $S B$ strain (ø black: 2.8, ø SB: 3.1).

Taking into account the experimental variability inherent to RNAi experiments, these data suggest that our strains do not have a generally different RNAi response. Moreover, the nucleic acid sequence of the dsRNA fragments is almost identical in both strains (99.4\%), making different RNAi efficiencies due to mismatches unlikely. Hence, the strain specific phenotypic difference we observed was likely due to different modulation of the Tc-importin $\alpha 1$ phenotype in the respective genetic backgrounds. This is similar to findings in other model organisms, where the phenotype of mutant alleles of some (but not all) genes is different depending on the genetic background of the strain.

\section{Tc-importin a1 peptide sequence is slightly diverged}

Next, we asked whether differences of the amino acid composition of Tc-importin $\alpha 1$ protein could be the reason for the differences. We isolated and sequenced the coding sequences of both strains. The Tc-importin $\alpha 1$ amino acid sequences (526 amino acids) of the black and $S B$ strains were aligned with the sequenced strain (GA-2) and with Importin $\alpha$ orthologs of other species.

The black and the GA-2 strains have identical sequences whereas the $S B$ strain has different amino acids at two sites (Figure 6, red frame) within the cargo binding ARM domains. The first site (position 147) is located within the second ARM domain, where the black and the GA-2 strains show a serine $(S)$ whereas the $S B$ strain shows an asparagine $(\mathrm{N})$. In metazoa, this position is either occupied by a threonine (T) (see examples given in Figure 6), serine (e.g. Saccoglossus kowalevskii) or asparagine (e.g. C. elegans) (not shown). All three amino acids are similar regarding their polar but uncharged side chains.

The second different amino acid is located within the eighth ARM domain (position 376). Here, the SB strain encodes a leucine (L, hydrophobic, not polar), whereas the two other Tribolium strains show a glutamine $(\mathrm{Q}$, polar uncharged), which is also found in the two hymenopterans Nasonia vitripennis ( $N$. vitripennis) and Apis mellifera (A. mellifera). M. musculus carries an alanine (A) at this position, which is hydrophobic and not polar, whereas $D$. melanogaster has a glutamic acid, which is acidic and negatively charged. None of the two sites is predicted to be the target of phosphorylation, N-glycosalation nor $\mathrm{N}$-myristoylation by ExPASy and Prosite analysis. Taken together, the observed amino acid substitutions may lead to altered binding affinities, which might influence the phenotype. However, this is difficult to test because we do not know which of the many nuclear proteins likely to be imported by Importin $\alpha$ s actually elicit the observed



Figure 6 Amino acid exchanges in the cargo binding domain of Importin a1 between the strains. Shown is a section of an alignment of Importin a proteins of different species and strains of Tribolium including the $2^{\text {nd }}, 7^{\text {th }}$ and $8^{\text {th }}$ ARM domains. GA2 is the sequenced strain. Black boxes represent identical amino acids, gray boxes denote sites with a conservation of about $90 \%$ and horizontal lines indicate the conserved ARM domains involved in cargo binding identified in S. cerevisiae SRP1 [48]. Red frames indicate two sites in which the amino acid sequence of the Tribolium strains differ. Both sites are within the region known to be responsible for cargo binding. Note, that other metazoans show $\mathrm{N}$ or $\mathrm{S}$ at the respective position within the ARM2 domain (see text for details). 
phenotypes. An alternative explanation would be that the mutations lead to differential splicing of the gene in the different strains.

\section{The maternal genotype mainly determines the Tc-importin a1 phenotype}

Our data hinted at the genetic background as cause for the different phenotypes. However, it remained open whether this would be based on zygotic gene expression (i.e. expression of the embryonic genome) or whether different maternal inputs would be involved (e.g. differential loading of the egg with respective protein or mRNA). In order to distinguish between these possibilities, Tc-importin $\alpha 1$ dsRNA $(1 \mu \mathrm{g} / \mu \mathrm{l})$ was injected in $S B$ and black females and these were afterwards mated with males of the other strain, respectively. Therefore, zygotic expression of genes was based on heterozygous condition for black/SB in all offspring while the maternal contribution was either of the black or the $S B$ type.

Offspring of injected $S B$ females mated with black males showed a similar phenotype as described for the $S B$ strain (compare Figure 7A with Figure 4B). In 23 analyzed cuticles the "abdomen inside-out" phenotype was most prominent (43.5\%). Besides, the "small abdomen" (13\%) and the "headless" (8.7\%) phenotype could also be observed in some cuticles. The "labrum only" phenotype was very rare (4.3\%). When Tc-importin $\alpha 1$ was knocked-down in black female pupae which were crossed to $S B$ males, the phenotypes were similar to the phenotype of the black strain (compare Figure 7B with Figure 4E). The labrum defects were most frequent (79.2\%), and in $50 \%$ the only affected structure. Also, the $S B$ typical "abdomen inside-out" phenotype was not observed.
These results show that it is primarily the genotype of the mother, which determines the quality of the Tc-importin $\alpha 1$ RNAi phenotype while the minor increase of "labrum only" phenotypes to $4,3 \%$ indicate some influence of the zygotic genome, too.

The importance of maternal contribution of Importin $\alpha$ proteins is plausible, because it is known from Drosophila that the transition from maternal to zygotic control occurs only at cell cycle $13-14[55,56]$. Already before this transition the nuclear import machinery is essential to allow gene activity. This is ensured by a strong maternal contribution [57-59].

\section{Relative maternal contribution of Tc-importin a 1 is reduced in the black strain}

Based on the fact that Importin $\alpha$ proteins act redundantly in the import of most proteins $[43,46]$ we asked whether the maternal supply of the oocyte with importin mRNAs would be different in the $S B$ and black strains. Specifically, we wanted to test the model that the contribution of maternal Tc-importin $\alpha 1$ was relatively small in the black strain and that this was buffered by increased Tc-importin $\alpha 2 / 3$ contributions. In that case, knock-down of Tc-importin $\alpha 1$ would lead to less prominent phenotypes in the black strain because most defects would be buffered by the other Importins $\alpha$ 's.

By quantitative RT-PCR, we determined the amount of mRNA present in ovaries where maternal load of oocytes takes place, freshly laid eggs which reflect the final maternal load and embryos at 10-12 hours of development, where zygotic transcription has started. The qPCR data were normalized to the expression of the ribosomal

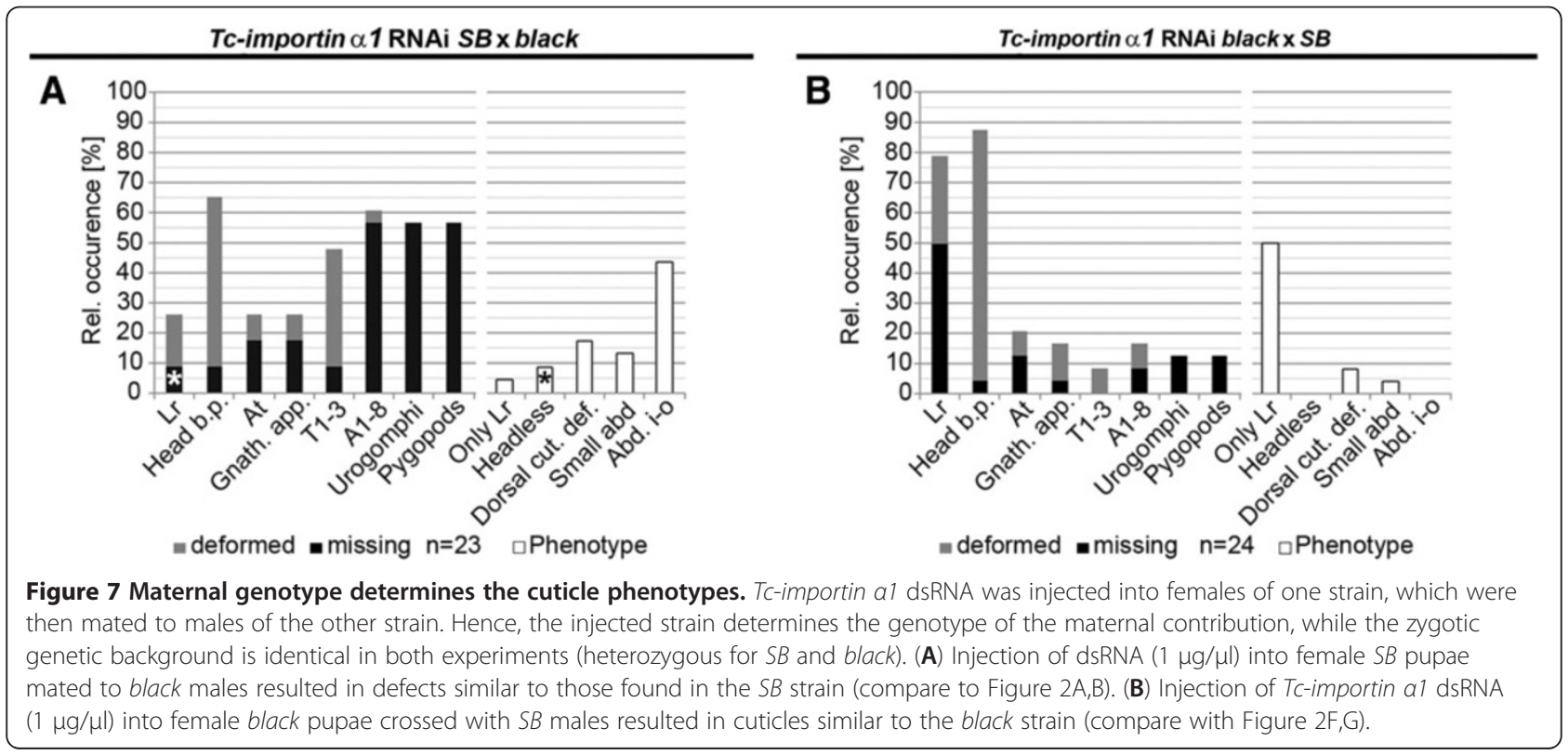


protein Tc-rpS3 within the samples [60] (Figure 8.). For better comparability between the strains, we subsequently standardized the datasets such that the Tc-importin $\alpha 1$ levels are identical in both strains (see Materials and Methods). This allowed detecting relative increase or decrease of the other importin $\alpha$ s. Both Tc-importin $\alpha 2$ and 3 levels were higher in all samples in the black strain compared to the $S B$ strain but none of these differences was significant.

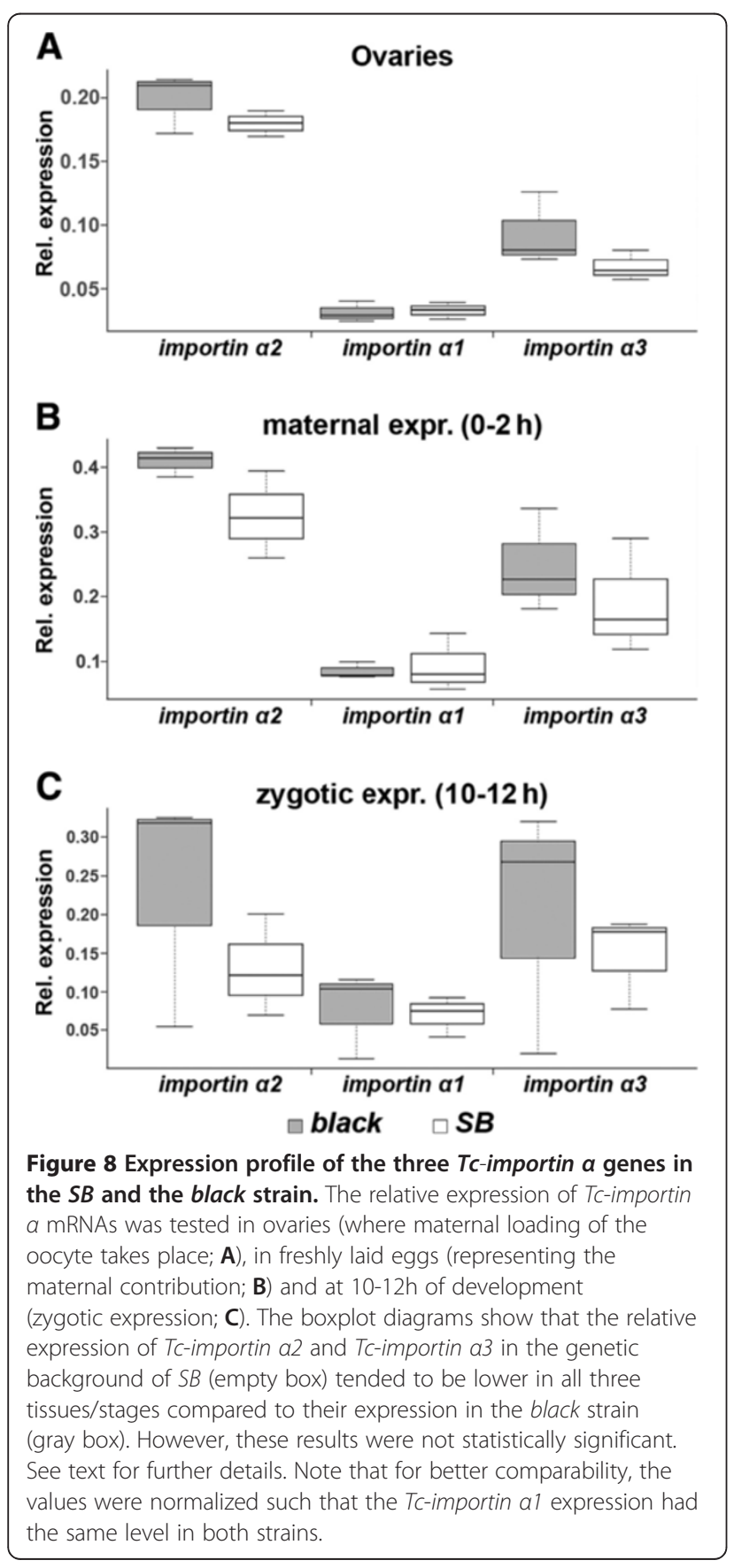

Maternal increase of Tc-importin a2 in Tc-importin a1 RNAi embryos in the black strain

An alternative possibility for different maternal buffering of the Tc-importin $\alpha$ paralogs was that the knock-down of Tc-importin $\alpha 1$ would be compensated by different patterns of upregulation of the other Tc-importin $\alpha$ paralogs in these strains. Indeed, in $0-2 \mathrm{~h}$ old embryos of Tc-importin $\alpha 1$ RNAi animals, the load of Tc-importin $\alpha 2$ was significantly increased in the black but not the $S B$ strain (see Additional file $1 \mathrm{~K}$ ). At this embryonic stage, maternal messages predominate, hence, it appears that maternal upregulation was involved in rescuing parts of the phenotype in the black strain. Interestingly, the situation was different when measuring zygotic transcript levels in 10-12h embryos. Here, the black transcript levels are not altered much, while in $S B$, Tc-importin $\alpha 2$ and 3 are upregulated. Apparently, the delayed compensation in $S B$ is too late to rescue the embryonic phenotype.

Potential mechanisms leading to the phenotypic differences This work was primarily aimed at showing that the quality of RNAi phenotypes may depend on the genetic background of the strain used. However, we also gained some insights into the potential mechanism how the difference might arise in the specific case of Tc-importin $\alpha 1$. Two things need to be explained: First, the absence of the expected pleiotropic defect, and second the occurrence of the qualitatively different "labrum only" phenotype in the black strain. To explain the apparent decrease of pleiotropic defects, we suggest that females of the black strain load their oocytes with more Tc-importin $\alpha 2$ and 3 relative to Tc-importin $\alpha 1$ and moreover, compensate for loss of Tc-importin $\alpha 1$ by upregulating Tc-importin $\alpha 2$. Therefore, the importin paralogs are able to rescue the knock-down effect of Tc-importin $\alpha 1$ much better in the black than in the $S B$ strain. This would lead to a comparably mild pleiotropic phenotype. Indeed, functional redundancies [61] and the resulting masking of phenotypes [49] by the different Importin $\alpha$ 's was described previously in Drosophila.

The black specific "labrum only" phenotype might depend on the strain specific amino acid changes found within the cargo binding domains. This difference may have allowed one or several target proteins required for labrum development to evolve an Importin $\alpha 1$ specific import signal. Loss of Tc-Importin $\alpha 1$ would be compensated by the paralogs for most proteins but not for the labrum specific protein, leading to the observed labrum specific phenotype. This model is in line with data showing that Importin paralogs besides their redundant roles in nuclear import of many proteins do also have paralog-specific cargoes [54,62]. A prerequisite for testing this model is the identification of all genes that lead to "no labrum" phenotypes. Then, these could be tested for differential binding with the different Importin $\alpha$ s. 
Alternatively, a higher relative expression of Tc-importin $\alpha 1$ in the labrum anlagen of the black strain could contribute to a "labrum only" phenotype. However, we were not able to detect differences in labral expression of Tc-importin $\alpha 1$ in the black and $S B$ strains by in situ hybridization. We might have missed mild modulations of expression-whether such minor differences would be able to lead to such a clear phenotype remains questionable. However, with the current data, we cannot exclude that the mechanism is much more complex and may involve many additional factors and interactions.

\section{Conclusions}

\section{Documentation of strains is essential for future RNAi} studies

It has been known from mice and Drosophila that different genetic backgrounds of laboratory inbred strains can affect the phenotypes in transgenic experiments (e.g. [6-8,63-65]. This may be due to changes within coding or non-coding regions [66]. Recently, Dworkin et al. argued that strain specific modulation of phenotypes may have to be considered more systematically than in the past [67]. Here, we show that this is also true for RNAi studies, which to our knowledge has not been considered in the past. Our findings have implications for the increasing number of RNAi experiments in an increasing number of animal taxa. First, discrepancies of results between labs might be due to the use of different strains. Second, the strain used in an RNAi experiment needs to be documented and kept over time to allow the reproduction of the phenotypes by others. Third, confirming the results of an RNAi experiment in another strain provides a good means to test for the general relevance of a phenotype.

\section{RNAi as tool for studying genetic differences on the population level}

Our finding also opens new possibilities. The ease of application of RNAi allows systematically identifying differences in gene regulatory networks between populations of one species including species that cannot be kept in the lab. Such changes provide the genetic variability, which is required for the evolution of novel traits. RNAi will allow a systematic investigation of the degree of variability within species.

\section{Methods}

\section{Cloning}

Tc-importin $\alpha 1$ open reading frame sequence (1581 bp; accession: [XM_963412]) was obtained from the iBeetle genome browser (http://bioinf.uni-greifswald.de/gb2/ gbrowse/tcas/). The following primers were used to amplify the open reading frame froman embryonic cDNA pool (0-48 h) via standard PCR: 5'-ATGTCG GGCTCCGCTCACAA-3' and 5'-TTAAAAATGGAAT
CCTCCCATCGGCACCG -3'. The Tc-importin $\alpha 1$ open reading frame was cloned into the pJET1.2 vector.

\section{RNAi}

The sequences of the fragments used for RNAi are given in the Additional file1 $\mathrm{B}$. The templates for the nonoverlapping fragments were generated by PCR from a plasmid template using following primers: 5'-TAATACGACT CACTATAGGAGTCTGGAGGAGGGTTCTTGC-3' and T7 Primer (5'-TAATACGACTCACTATAGG-3') for the 5' fragment (Tc-importin $\alpha 1 \mathrm{a}, 709 \mathrm{bp}$; see Additional file $1 \mathrm{~A}$ and $\mathrm{B}$, gray bar) and 5'-TAATACGACTCACTATAGGT TGCGAAAGTCTCCCCAGCT-3' and pJET1.2R sequencing primer with a T7-attachment (5'-TAATACGACT CACTATAGGAAGAACATCGATTTTCCATGGCAG-3’) for the 3' fragment (Tc-importin $\alpha 1 \mathrm{~b}, 872 \mathrm{bp}$; see Additional file $1 \mathrm{~A}$ and $\mathrm{B}$, black bar). Concentrations for parental RNAi were $0.3 \mu \mathrm{g} / \mu \mathrm{l}, 1 \mu \mathrm{g} / \mu \mathrm{l}$ and $3 \mu \mathrm{g} / \mu \mathrm{l}$ (Tc-importin $\alpha 1 \mathrm{a}$ and Tc-importin $\alpha \mathrm{lb}), 1 \mu \mathrm{g} / \mu \mathrm{l}(T c-g t$ and $T c-d l l)$ and for larval RNAi $1 \mu \mathrm{g} / \mu \mathrm{l}(T c-w g)$ and $0.5 \mu \mathrm{g} / \mu \mathrm{l}$ (Tc-six3). Pupal injections were performed as described [32]. For larval RNAi (IRNAi) the larvae were anaesthetized by cooling them on ice. The dsRNA was injected using the FemtoJet express (eppendorf, Hamburg). Late larval stages (L6) were injected into the ventro-lateral side between the fifth and sixth abdominal segment. On average 0.4-0.5 $\mu \mathrm{l}$ dsRNA were injected into one larva. Injected larvae were raised as described [34].

\section{Microscopy and Image analysis}

Cuticles were documented using a Zeiss LSM 510 as described [68,69]. Tc-dll RNAi legs were recorded in 15 focal planes using a Zeiss Axioplan microscope and ImagePro Plus software (MediaCybernetics ${ }^{\circledR}$, version 6.2). Deconvolution was performed with the "No Neighbour" method followed by a maximum projection using ImageJ (version 1.44 o). Pupae were analyzed and documented using a Leica M205 FA fluorescence stereomicroscope.

IRNAi pupae were analyzed using ImageJ (version 1.44 o). The diameter of the second segment of the maxillary palpus (Figure 5C, white arrowhead) was measured using the straight line tool. Division in phenotypic levels: Level $1=$ wild-type $(\mathrm{wt})$ range of diameter, level $2=$ minimum $\mathrm{wt}$ diameter minus wt range, level $3=$ minimum level 2 diameter minus wt range, level $4=$ minimum level 3 diameter minus wt range. The eye field area of both eyes in Tc-six3 IRNAi in late pupal stages (fully sclerotized mandibles) was measured by freehand selection tool and the mean was calculated. The mean value provided the basis for the phenotype comparison. The phenotype level was chosen arbitrarily.

\section{Phylogenetic analysis}

Importins of the different species were obtained using amino acid sequence of Tc-Importin $\alpha 1$ as query for a 
BLASTp search [70] at NCBI (http://blast.ncbi.nlm.nih. gov/Blast.cgi, Figure S2). Phylogenetic analysis was conducted using MEGA version 5 [71]. The multiple alignment was done using the ClustalW application with the preset parameters. A phylogenetic tree was calculated using the Neighbor-joining method under the Poisson amino acid substitution model. Bootstrap analysis was conducted using 1000 replicates to test the robustness of the phylogenetic tree. Calculation of a phylogenetic tree using the Maximum-Likelihood method under the Jones-TaylorThornton model amino acid substitution model results in essentially the same phylogenetic tree.

\section{Correspondence analysis}

For correspondence analysis [72], the labrum, head bristle pattern, antennae, gnathal appendages, thoracal segments, abdominal segments, pygopods and urogomphi of each L1 cuticle were classified into three different categories: not affected $=0$, deformed $=0.5$ and absent $=1$. The dataset was imported into $\mathrm{R}$ (v. 2.14.2, [73]) and correspondence analysis and plotting was performed by using the $\mathrm{R}$ 'ca' package [74].

\section{Quantitative RT-PCR}

Total RNA was isolated from dissected ovaries of adult beetles using the Tissue \& Insect RNA MicroPrep ${ }^{\text {TM }}$ Kit (Zymo Research Corporation, Irvine) and from eggs (0-2 h and 10-12 h) using TRIzol ${ }^{\circledR}$ reagent (Ambion ${ }^{\circledR} /$ Live technologies, New York). $1 \mu \mathrm{g} / \mu \mathrm{l}$ total RNA was converted to cDNA by using the MAXIMA ${ }^{\circledR}$ First Strand cDNA Synthesis Kit for RT-qPCR (Thermo Scientific, Waltham). Quantitative PCR was performed using HOT FIREPol ${ }^{\circledR}$ EvaGreen ${ }^{\circledR}$ qPCR Mix Plus (ROX) (Solis BioDyne, Tartu) and the CFX96 ${ }^{\mathrm{TM}}$ Real-Time PCR System (Bio-Rad Laboratories, Hercules). For the qRT-PCR the following primer pairs were used: Tc-importin $\alpha 1$ : 5'-CCGTATGCTGTGCT AATCGAG-3' and 5'-CGTCCCGAAGAAGTGTTCAAT3', Tc-importin $\alpha 2$ : 5'AAAGTCTACGAACGGGCTTTG-3' and 5'-GAACTGAATCTCCCCATTTGC-3', Tc-importin a3: 5'-TGAGGAGTGCAATGGCTTAGA-3' and 5'TCAT CCGCATCACCACTAAAG-3' and Tc-rpS3: 5'-ACCTCGA TACACCATAGCAAGC-3' and 5'-ACCGTCGTATTCGT GAATTGAC-3'. All primers were designed to span an intronic sequence and were validated by gel analysis. To calculate primer efficiency $\left(E=10^{\wedge}(-1 / \mathrm{m})\right)$, a dilution series was performed. Data was normalized by the formula: rel. expression $=\mathrm{R}_{\text {target }}{ }^{\wedge} \mathrm{C} \mathrm{q}_{\text {target }} / \mathrm{R}_{\text {ref. }}{ }^{\wedge} \mathrm{Cq}$ ref. For better comparison of the results in the two strains, the expression levels were normalized such that the genes with the lowest relative expression were set to the same values in the $S B$ and black strains. Specifically, the difference between the means of Tc-importin $\alpha 1$ expression levels in the $S B$ and the black strains were calculated. Subsequently, all $S B$ expression levels were reduced by this mean difference (Figure 8). This normalization was not done for Additional file $1 \mathrm{~K}$. For statistical analysis, three tests were performed: Welch's t-test, Student's t-Test and the Mann-Whitney-U-test. None of these tests revealed significant differences between the respective expression profiles in $S B$ and black.

\section{Additional file}

Additional file 1: Genomic structure of Tc-importin a1, dsRNA fragments, alignments, tables with cuticle analyses, Tc-importin a1 RNAi phenotype in the GA-2 and pig19 strains, qPCR of importin paralogs in Tc-importin a1 RNAi.

\section{Competing interests}

The authors declare that they have no competing interests.

\section{Authors' contributions}

JS identified the phenotype in the iBeetle screen, PK did the experiments, analyzed the data and wrote the manuscript, CSE contributed to the design of the study and the analysis of the data, GB conceived of the study, analyzed the data and finalized the manuscript. All authors read and approved the final manuscript.

\section{Acknowledgements}

We thank the DFG research unit FOR1234 for funding and the members of the iBeetle consortium for discussion. We thank Sebastian Kittelmann for critically reading the manuscript, Nico Posnien and Georg Oberhofer for help with the statistical analysis and $\mathrm{qPCR}$ and Ernst A. Wimmer for continuous support.

Received: 13 August 2012 Accepted: 19 December 2012

Published: 16 January 2013

\section{References}

1. St Johnston D: The art and design of genetic screens: Drosophila melanogaster. Nat Rev Genet 2002, 3:176-188.

2. Casselton L, Zolan M: The art and design of genetic screens: filamentous fungi. Nat Rev Genet 2002, 3:683-697.

3. Jorgensen EM, Mango SE: The art and design of genetic screens: caenorhabditis elegans. Nat Rev Genet 2002, 3:356-369.

4. Page DR, Grossniklaus U: The art and design of genetic screens: Arabidopsis thaliana. Nat Rev Genet 2002, 3:124-136.

5. Patton EE, Zon LI: The art and design of genetic screens: zebrafish. Nat Rev Genet 2001, 2:956-966.

6. Threadgill DW, Dulgosz AA, Hansen LA, Tennenbaum T, Lichti U, Yee D, LaMantia C, Mourton T, Herrup K, Harris RC, et al: Targeted Disruption of Mouse EGF Receptor: Effect of Genetic Background on Mutant Phenotype. Science 1995, 269:230-234.

7. Dworkin I, Kennerly E, Tack D, Hutchinson J, Brown J, Mahaffey J, Gibson G: Genomic Consequences of Background Effects on scalloped Mutant Expressivity in the Wing of Drosophila melanogaster. Genetics 2009, 181:1065-1076.

8. Linder CC: Genetic Variables That Influence Phenotype. ILAR J 2006, 47:132-140

9. Crossin KL: Functional role of cytotactin/tenascin in morphogenesis: a modest proposal. Perspect Dev Neurobiol 1994, 2:21-32.

10. Pickett FB, Meeks-Wagner DR: Seeing double: appreciating genetic redundancy. Plant Cell 1995, 7:1347-1356.

11. Lander ES, Schork NJ: Genetic dissection of complex traits. Science 1994, 265:2037-2048.

12. Gibson $\mathrm{G}$, van Helden S: Is function of the Drosophila homeotic gene Ultrabithorax canalized? Genetics 1997, 147:1155-1168.

13. Dworkin I: A study of canalization and developmental stability in the sternopleural bristle system of Drosophila melanogaster. Evolution 2005, 59:1500-1509.

14. Remold SK, Lenski RE: Pervasive joint influence of epistasis and plasticity on mutational effects in Escherichia coli. Nat Genet 2004, 36:423-426. 
15. Cao $Y$, Ding $X$, Cai M, Zhao J, Lin Y, Li X, Xu C, Wang S: The expression pattern of a rice disease resistance gene xa3/xa26 is differentially regulated by the genetic backgrounds and developmental stages that influence its function. Genetics 2007, 177:523-533.

16. Felix MA: Cryptic quantitative evolution of the vulva intercellular signaling network in Caenorhabditis. Curr Biol 2007, 17:103-114.

17. Dowell RD, Ryan O, Jansen A, Cheung D, Agarwala S, Danford T, Bernstein DA, Rolfe PA, Heisler LE, Chin B, et al: Genotype to phenotype: a complex problem. Science 2010, 328:469.

18. Nusslein-Volhard C, Wieschaus E: Mutations affecting segment number and polarity in Drosophila. Nature 1980, 287:795-801.

19. Miklos $G \mathrm{~L}$, Rubin GM: The role of the genome project in determining gene function: insights from model organisms. Cell 1996, 86:521-529.

20. Trauner J, Schinko J, Lorenzen MD, Shippy TD, Wimmer EA, Beeman RW Klingler M, Bucher G, Brown SJ: Large-scale insertional mutagenesis of a coleopteran stored grain pest, the red flour beetle Tribolium castaneum, identifies embryonic lethal mutations and enhancer traps. BMC Biol 2009, 7:73

21. Pultz MA, Zimmerman KK, Alto NM, Kaeberlein M, Lange SK, Pitt JN, Reeves NL, Zehrung DL: A Genetic Screen for Zygotic Embryonic Lethal Mutations Affecting Cuticular Morphology in the Wasp Nasonia vitripennis. Genetics 2000, 154:1213-1229.

22. Sulston IA, Anderson KV: Embryonic patterning mutants in Tribolium castaneum. Development 1996, 122:805-814.

23. Fire A, Xu S, Montgomery MK, Kostas SA, Driver SE, Mello CC: Potent and specific genetic interference by double-stranded RNA in Caenorhabditis elegans. Nature 1998, 391:806-811.

24. Mello CC, Conte DJ: Revealing the world of RNA interference. Nature 2004, 431:338-342.

25. Filipowicz W: RNAi: The Nuts and Bolts of the RISC Machine. Cell 2005, 122:17-20.

26. Meister G, Tuschl T: Mechanisms of gene silencing by double-stranded RNA. Nature 2004, 431:343-349.

27. van Mierlo JT, van Cleef KWR, van Rij RP: Defense and Counterdefense in the RNAi-Based Antiviral Immune System in Insects. Methods Mol Biol 2011, 721:3-22

28. Ketting RF: The Many Faces of RNAi. Dev Cell 2011, 20:148-161

29. Feinberg EH, Hunter CP: Transport of dsRNA into Cells by the Transmembrane Protein SID-1. Science 2003, 301:1545-1547.

30. Shih JD, Hunter CP: SID-1 is a dsRNA-selective dsRNA-gated channel. RNA 2011, 17:1057-1065.

31. Tomoyasu Y, Miller SC, Tomita S, Schoppmeier M, Grossmann D: B G.: Exploring systemic RNA interference in insects: a genome-wide survey for RNAi genes in Tribolium. Genome Biol 2008, 3:R10.1-R10.22

32. Bucher G, Scholten J, Klingler M: Parental RNAi in Tribolium (Coleoptera). Curr Biol 2002, 12:R85-R86.

33. Brown SJ, Mahaffey JP, Lorenzen MD, Denell RE, Mahaffey JW: Using RNAi to investigate orthologous homeotic gene function during development of distantly related insects. Evol Dev 1999, 1:11-15.

34. Tomoyasu Y, Denell RE: Larval RNAi in Tribolium (Coleoptera) for analyzing adult development. Dev Genes Evol 2004, 214:575-578.

35. Arakane Y, Muthukrishnan S, Kramer KJ, Specht CA, Tomoyasu Y, Lorenzen MD, Kanost M, Beeman RW: The Tribolium chitin synthase genes TcCHS1 and TcCHS2 are specialized for synthesis of epidermal cuticle and midgut peritrophic matrix. Insect Mol Biol 2005, 14:453-63.

36. Beermann A, Jay DG, Beeman RW, Hülskamp M, Tautz D, Jürgens G: The Short antennae gene of Tribolium is required for limb development and encodes the orthologue of the Drosophila Distal-less protein. Development 2001, 128:287-297.

37. Cerny AC, Bucher G, Schröder R, Klingler M: Breakdown of abdominal patterning in the Tribolium Krüppel mutant jaws. Development 2005, 132:5353-5363.

38. Bucher $\mathrm{G}$, Klingler M: Divergent segmentation mechanism in the short germ insect Tribolium revealed by giant expression and function. Development 2004, 131:1729-1740.

39. Bolognesi R, Farzana L, Fischer TD, Brown SJ: Multiple Wnt Genes Are Required for Segmentation in the Short-Germ Embryo of Tribolium castaneum. Curr Biol 2008, 18:1624-1629.

40. Posnien N, Bashasab F, Bucher G: The insect upper lip (labrum) is a nonsegmental appendage-like structure. Evol Dev 2009, 11:480-488.
41. Sokoloff A, Slatis HM, Stanley J: The black Mutation in Tribolium castaneum. J Hered 1960, 52:131-135.

42. Lorenzen MD, Berghammer AJ, Brown SJ, Denell RE, Klingler M, Beeman RW: PiggyBac-mediated germline transformation in the beetle Tribolium castaneum. Insect Mol Biol 2003, 12:433-440.

43. Mosammaparast N, Pemberton LF: Karyopherins: from nuclear-transport mediators to nuclear-function regulators. Trends Cell Biol 2004, 14:547-556.

44. Köhler M, Speck C, Christiasen M, Bischoff FR, Prehn S, Haller H, Görlich D, Hartmann E: Evidence for Distinct Substrate Specificities of Importin a Family Members in Nuclear Protein Import. Mol Cell Biol 1999, 19:7782-7791.

45. Lange A, Ryan EM, Lange CJ, Stewart M, Devine SE, Corbett AH: Classical Nuclear Localization Signals: Definition, Function, and Interaction with Importin a. JBC 2007, 282:5101-5105.

46. Lusk CP, Blobel G, King MC: Highway to the inner nuclear membrane: rules for the road. Nat Rev Mol Cell Bio 2007, 8:414-420.

47. Fontes MRM, Teh T, Kobe B: Structural Basis of Recognition of Monopartite and Bipartite Nuclear Localization Sequences by Mammalian Importin-a. J Mol Biol 2000, 297:1183-1194.

48. Conti E, Uy M, Leighton L, Blobel G, Kuriyan J: Crystallographic Analysis of the Recognition of a Nuclear Localization Signal by the Nuclear Import Factor Karyopherin a. Cell 1998, 94:193-204.

49. Ratan R, Mason DA, Sinnot B, Goldfarb DS, Fleming RJ: Drosophila Importin a1 Performs Paralog-Specific Functions Essential For Gametogenesis. Genetics 2008, 178:839-850

50. Prieve MG, Guttridge KL, Munguia J, Waterman ML: Differential Importin-a Recognition and Nuclear Transport by Nuclear Localization Signals within the High-Mobility-Group DNA Binding Domains of Lymphoid Enhancer Factor 1 and T-Cell Factor 1. Mol Cell Biol 1998, 18:4819-4832.

51. Prieve MG, Guttridge KL, Munguia JE, Waterman ML: The Nuclear Localization Signal of Lymphoid Enhancer Factor-1 Is Recognized by Two Differentially Expressed Srp1-Nuclear Localization Sequence Receptor Proteins. J Biol Chem 1996, 271:7654-7658.

52. Talcott B, Moore MS: The Nuclear Import of RCC1 Requires a Specific Nuclear Localization Sequence Receptor, Karyopherin a3/Qip. J Biol Chem 2000, 275:10099-10104

53. Fagerlund R, Melen K, Kinnunen L, Julkunen I: Arginine/Lysine-rich Nuclear Localization Signals Mediate Interactions between Dimeric STATs and Importin a5. J Biol Chem 2002, 277:30072-30078.

54. Quensel C, Friedrich B, Sommer T, Hartmann E, Köhler M: In Vivo Analysis of Importin a Proteins Reveals Cellular Proliferation Inhibition and Substrate Specificity. Mol Cell Biol 2004, 24:10246-10255.

55. Tadros W, Westwood JT, Lipshitz HD: The Mother-to-Child Transition. Cell 2007, 12:847-849.

56. Abe Y, Oka A, Mizuguchi M, Igarashi T, Ishikawa S, Aburatani H, Yokoyama S, Asahara H, Nagao K, Yamada M, et al: EYA4, deleted in a case with middle interhemispheric variant of holoprosencephaly, interacts with SIX3 both physically and functionally. Hum Mutat 2009, 30:E946-55.

57. Tirian L, Puro J, Erdelyi M, Boros I, Papp B, Lippai M, Szabad J: The KetelD Dominant-Negative Mutations Identify Maternal Function of the Drosophila Importin-b Gene Required for Cleavage Nuclei Formation. Genetics 2000, 156:1901-1912.

58. Garcia-Solache M, Jaeger J, Akam M: A systematic analysis of the gap gene system in the moth midge Clogmia albipunctata. Dev Biol 2010, 344:306-18.

59. Yurrtas $P$, Morency E, Coonrod SA: Use of proteomics to identify highly abundant maternal factors that drive the egg-to-embryo transition. Reproduction 2010, 139:809-823.

60. Lord JC, Hartzer K, Toutges M, Oppert B: Evaluation of quantitative PCR reference genes for gene expression studies in Tribolium castaneum after fungal challenge. J Microbiol Methods 2010, 80:219-221.

61. Goldfarb DS, Corbett AH, Mason DA, Harreman MT, Adam SA: Importin a: a multipurpose nuclear-transport receptor. Trends Cell Biol 2004, 14:505-514.

62. Friedrich B, Quensel C, Sommer T, Hartmann E, Köhler M: Nuclear Localization Signal and Protein Context both Mediate Importin a Specificity of Nuclear Import Substrates. Mol Cell Biol 2006, 26:8697-8703.

63. Polaczyk PJ, Gasperini R, Gibson G: Naturally occurring genetic variation affects Drosophila photoreceptor determination. Dev Genes Evol 1998, 207:462-470.

64. Nuzhdin SV, Brisson JA, Pickering A, Wayne ML, Harshman LG, Mclntyre L: Natural genetic variation in transcriptome reflects network structure inferred with major effect mutations: insulin/TOR and associated phenotypes in Drosophila melanogaster. BMC Genomics 2009, 10:124. 
65. Leonard JR, Klocke BJ, D'Sa C, Flavell RA, Roth KA: Strain-Dependent Neurodevelopmental Abnormalities in Caspase-3-Deficient Mice. J Neuropathol Exp Neurol 2002, 61:673-677.

66. Keane TM, Goodstadt L, Danecek P, White MA, Wong K, Yalcin B, Heger A, Agam A, Slater G, Goodson M, et al: Mouse genomic variation and its effect on phenotypes and gene regulation. Nature 2011, 477:289-294.

67. Chandler CH, Chari S, Dworkin I: Does your gene need a background check? How genetic background impacts the analysis of mutations, genes, and evolution. $T / G$ in press.

68. Wohlfrom $\mathrm{H}$, Schinko JB, Klingler M, Bucher G: Maintenance of segment and appendage primordia by the Tribolium gene knödel. Mech Dev 2006, 123:430-439.

69. Richards S, Gibbs RA, Weinstock GM, Brown SJ, Denell R, Beeman RW, Gibbs R, Beeman RW, Brown SJ, Bucher G, et al: The genome of the model beetle and pest Tribolium castaneum. Nature 2008, 452:949-55.

70. Altschul SF, Gish W, Miller W, Myers EW, Lipman DJ: Basic local alignment search tool. J Mol Biol 1990, 215:403-410.

71. Tamura K, Peterson D, Peterson N, Stecher G, Nei M, Kumar S: MEGA5: Molecular Evolutionary Genetics Analysis using Maximum Likelihood, Evolutionary Distance, and Maximum Parsimony Methods. Mol Biol Evol 2011, 28:2731-2739

72. Benzécri JP: L'Analyse des Données. Paris: Dunod; 1973.

73. Team RDC: R: A language and environment for statistical computing. Vienna: R Foundation for Statistical Computing; 2012.

74. Nenadic O, Greenacre M: Correspondence Analysis in R, with two- and three-dimensional graphics: The ca package. J Stat Softw 2007, 20:1-13.

doi:10.1186/1471-2164-14-5

Cite this article as: Kitzmann et al:: RNAi phenotypes are influenced by the genetic background of the injected strain. BMC Genomics 2013 14:5.

\section{Submit your next manuscript to BioMed Central and take full advantage of:}

- Convenient online submission

- Thorough peer review

- No space constraints or color figure charges

- Immediate publication on acceptance

- Inclusion in PubMed, CAS, Scopus and Google Scholar

- Research which is freely available for redistribution 